\title{
Applying and Evaluating Understanding-Oriented ICT User Training in Upper Secondary Education
}

\author{
Cornelia Brodahl, Marit Fagernes, Said Hadjerrouit \\ Faculty of Mathematics and Sciences \\ Agder University Collage, Kristiansand, Norway
}

\author{
Cornelia.Brodahl@hia.no, Marit.Fagernes@hia.no, \\ Said.Hadjerrouit@hia.no
}

\begin{abstract}
ICT training courses have recently undergone some important changes. These changes are made possible by new pedagogical approaches to ICT training. As a result, the focus has changed from memorizing, recall and reproduction of knowledge to conceptual understanding of the underlying software. One of these approaches is the Herskin's understanding-oriented ICT training method. This paper assesses students' learning when confronted with the task of implementing this method. More specifically, it addresses critical factors of success and potential obstacles when implementing the ICT training method in upper secondary schools. It also presents teacher students' common misconceptions and simplifications when practicing the method for the first time. Finally, the article outlines a framework for rethinking ICT training within constructivist learning environments.
\end{abstract}

Keywords: Constructivism, Hands-on, ICT training method, instruction sheet, learning theory teacher education.

\section{Introduction}

ICT (Information and Communication Technology) training courses often do not provide understanding of software on a deeper level than memorizing the correct buttons and menu command to press (Sein, Bostrom \& Olfman, 1998). Poor understanding of problem-related solution principles, missing procedure overview as well as need for navigation aid to find the right place in complex software, become a serious problem when the users will experience the learned skills.

Herskin (2004a, 2004b) presents an ICT user training method that is supposed to provide the students with a more thorough understanding of the software (Herskin \& Herskin, 2005). The method is presented as "user friendly ICT training". Herskin's reasoning and practical experiences are related to training courses for adult students.

Material published as part of this publication, either on-line or in print, is copyrighted by the Informing Science Institute. Permission to make digital or paper copy of part or all of these works for personal or classroom use is granted without fee provided that the copies are not made or distributed for profit or commercial advantage AND that copies 1) bear this notice in full and 2) give the full citation on the first page. It is permissible to abstract these works so long as credit is given. To copy in all other cases or to republish or to post on a server or to redistribute to lists requires specific permission and payment of a fee. Contact Publisher@InformingScience.org to request redistribution permission.
Aiming at evaluating the applicability of Herskin's method in upper secondary schools in future studies, the authors of this paper intend in this preliminary study to involve teacher students in adopting the method and applying it in their teaching practice. The research interest of this study is whether teacher students, having a university degree in informatics, are able to apply Herskin's method in their teaching practice. And, 
if not, to identify critical factors of success that require attention to be given in futures studies.

The article is organized as follows. First, the paper presents the research issues of the work. Second, conventional ICT training approaches are described and compared to Herskin's ICT method. The method is then compared to learning theory. Third, students' research-based tasks and the conditions of the experimentation with Herskin's method are presented. This is followed by the evaluation methods and results of student's application of the ICT training method in upper secondary schools. The results are then discussed from different perspectives and stakeholders. Finally, some remarks on further work conclude the paper.

\section{Research Issues}

The underlying hypothesis of this work is that Herskin's method has the potential to improving ICT training courses in upper secondary schools. It should not be limited to a single preliminary experiment since valuable research results and possible learning benefits can be achieved only through the iterative and continuous cycle of design, implementation, evaluation, and redesign of the ICT training method in varied school contexts.

Basically, the objectives of this preliminary study are three research issues:

1. To critically evaluate Herskin's ICT user training method in light of learning theories, in particular cognitive constructivism and social constructivism, in order to reflect on the pedagogical assumptions of the ICT training method.

2. To report and evaluate an implementation of it in upper secondary schools, and to find out whether the teacher students, having a university degree in informatics, are able to apply it in compliance with the basic principles of the method.

3. To critically discuss the limitations and potentialities of the method, as well as critical factors of success that require attention to be given when introducing a new ICT training method in upper secondary schools.

\section{Conventional ICT User Training}

Conventional ICT user training courses have two major components:

- The overview, and

- Hands-on exercise.

During the overview the teacher uses a video projector and a big screen to present the program functions, and demonstrates how the following hands-on exercise should be solved. The students then work on their own, trying to remember this procedure.

Empirically, this is an inefficient teaching method, and therefore the teacher compensates by using solutions that only treat the symptoms, for instance teaching small groups, splitting the lessons in smaller parts. Some teachers adopt the "Pinocchio model", where the students act as puppets following the puppet player's movement i.e. the teacher's keystrokes. Kaasbøll (Kaasbøll, 2002) refers to this method as the "parrot model". Another common action is to provide the students with detailed key manuals showing how the exercise should be solved step-by-step. However, all these solutions do not change the basic problems.

According to Herskin, the limitations of conventional ICT user training courses consist of three basic problems:

1. The memory problem: The student must remember a detailed procedure. 
2. The understanding problem: The student has not understood the principles of how to solve the exercise.

3. The dependence problem: The student is not able to work on his own solving the exercise.

To solve these problems, Herskin proposes four ICT pedagogical principles, and from these he builds his own method:

1. The pedagogical mission in ICT training courses involves a shift from content to methods.

2. The goal of ICT training courses is to help students to become independent learners.

3. The pedagogical strategy consists of two strictly separated phases: A presentation or overview phase and a task-based or exercise phase.

4. Teaching techniques are concerned with using "understanding tools" that provide support for understanding the underlying principles of software.

\section{Understanding-Oriented ICT User Training}

Herskin's understanding-oriented ICT user training method is an alternative and new way of teaching ICT training courses. To understand this method, it is important to reflect on the underlying principles of the new method, and how it differs from conventional ICT training approaches.

Herskin's method is based on an analytic view of the learning processes. Herskin identifies the single steps in the learning processes and the problems associated with those. He reduces possible solutions for each of them to an overall system. Herskin considers this approach to be an innovative ICT training method. Basically, Herskin's ICT training method consists of the following parts:

- Overview (presentation)

- Instruction sheet

- Exercise

- Summary

The important objective is to remove the details needed to be remembered, using a problemoriented understanding process, and changing focus from "how to perform the software functions?" to "why to perform those functions?", that is from memorizing to understanding.

\section{Overview Phase}

In the overview phase the teacher uses what Herskin calls "understanding tools". These could be examples, visualizing and dialogues. The objective of this phase is generating understanding. By using situated examples, the teacher should enable the students to understand the problem. The principles are then explained through visualizing, and finally the teacher gives a procedure overview using visual boxes that shows the main steps of the whole process.

This is what Herskin calls three P's:

- The Problem

- The Principles

- The Procedural overview 


\section{Instruction Sheet and Exercise}

Before the students do the exercise on their own, an instruction sheet for this kind of tasks is handed out. An important issue for the teacher is not to mix the instruction sheet and the exercise. The instruction sheet should give a generalized explanation on how to solve this kind of tasks. The exercise itself should only describe the problem, not telling how to solve it.

The fundamental idea behind the instruction sheet is to provide the user with a brief manual, which could be used both during the hands-on phase of the course, and in the users' daily work with the software. The aim is to enable the user to meet challenges less reliant to the teacher's assistance. The instruction sheet should not contain any screen shots, but make the user pay attention to information in menus and dialogue boxes in the software. According to Herskin, the instruction sheet should be separated in three columns:

- Column 1 gives a procedural overview (heading: "phase")

- Column 2 explains and describes why to perform this step (heading: "why"). This column could be left blank for the user to fill in.

- Column 3 leads the user to the correct menu, dialogue box etc. (heading: "interaction")

An instruction sheet for check spelling in a given text document is illustrated in Table 1.

\section{Summary Phase}

Finally, the students get the opportunity to raise questions regarding the specific exercise or more general problems. The teacher can provide supplementary information (such as tricks). In this phase the students might also discuss how the software functions could be used in other situations.

\section{User ICT Training and Learning Theory}

As for any instructional approach the very basis of Herskin's ICT training method should be a pedagogical foundation based on learning theories. It is thus important to analyze the pedagogical assumptions of the ICT training method.

\section{Learning Theories}

Literature reviews suggest that learning theories can be related to three main commonly accepted paradigms (Phillips \& Soltis, 1998):

- Behaviorism

- Cognitive/psychological constructivism

- Social constructivism

The behaviorist paradigm assumes the existence of objective knowledge independent of the learners whereas the cognitive and social constructivist paradigms view knowledge as a constructed entity made by each learner and group of learners through a learning process.

In terms of instruction, behaviorism assumes that the goal of learning is to efficiently transmit knowledge from the instructor to the learners. Learning is seen as largely as a passive process. In a behaviorist setting, instructors are clearly central to learning activities. As a result, there are few opportunities for learners to express their own ideas during the course of instruction. The behaviorist model is therefore criticized for stimulating surface learning, memorization, and knowledge reproduction. 
Table 1: Instruction sheet for check spelling in a given text document

\section{Instruction Sheet}

Issue: Check spelling in your document

\section{Program: Office desktop programs}

You can check the spelling of your document content using dictionaries in office desktop programs. You can check as you type in or after typing, provided that the dictionary file for the language you use is installed on you computer. You can build your own customer dictionary that will be used in addition to the main dictionaries.

\begin{tabular}{|c|c|c|}
\hline Phase & Why & Interaction \\
\hline Select language & $\begin{array}{l}\text { The program may provide dictionaries in several lan- } \\
\text { guages and needs information about the language(s) } \\
\text { used in your document. You may declare the language } \\
\text { as you type or later. }\end{array}$ & $\begin{array}{l}\text { Tools | Language | Set lan- } \\
\text { guage ... }\end{array}$ \\
\hline $\begin{array}{l}\text { Turn on/off } \\
\text { automatic language } \\
\text { detection }\end{array}$ & $\begin{array}{l}\text { If your document contains more than one language, the } \\
\text { program may automatically detect each language you } \\
\text { type, provided the actual language file is available. }\end{array}$ & $\begin{array}{l}\text { Select or deselect } \\
\text { the Detect language auto- } \\
\text { matically check box }\end{array}$ \\
\hline $\begin{array}{c}\text { Configure } \\
\text { Check Spelling }\end{array}$ & $\begin{array}{l}\text { The program lets you set different spelling options. You } \\
\text { may turn on/off the spelling checker to decide if spell- } \\
\text { ing will be checked as you type in. }\end{array}$ & $\begin{array}{l}\text { Tools } \mid \text { Options } \mid \text { Spelling } \\
\text { \& Grammar } \mid \text { Spelling }\end{array}$ \\
\hline $\begin{array}{l}\text { Spell check } \\
\text { your work }\end{array}$ & $\begin{array}{l}\text { If spell checking is turned off as you type in, you may } \\
\text { run it to check a single word, a part of your word or } \\
\text { your whole document. When the spelling checker finds } \\
\text { a word that is not contained in the dictionary or if the } \\
\text { same word appears twice and successively, it opens the } \\
\text { Spelling dialog and shows word/s in red colour in the } \\
\text { surrounding text. Suggested corrections are listed. }\end{array}$ & $\overline{A B C}$ \\
\hline Accept & $\begin{array}{l}\text { You may choose to accept the suggestion and keep the } \\
\text { word as you typed it (1), or you may accept the sug- } \\
\text { gested correction throughout the document (2). }\end{array}$ & $\begin{array}{l}\text { Highlight the suggestion } \\
\text { and click the Change (1) or } \\
\text { Change All (2) button. If } \\
\text { the correct word doesn't } \\
\text { appear in the list, you can }\end{array}$ \\
\hline Ignore & $\begin{array}{l}\text { You may choose to ignore the suggestion and keep the } \\
\text { word as you typed it (1), or you may ignore the sug- } \\
\text { gested correction throughout the document (2). }\end{array}$ & 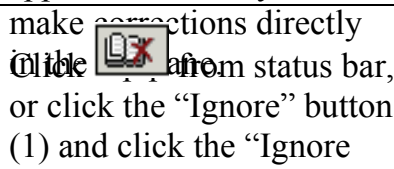 \\
\hline $\begin{array}{l}\text { Add a word to dic- } \\
\text { tionary }\end{array}$ & $\begin{array}{l}\text { If the spelling checker marks a word, it does not neces- } \\
\text { sarily mean that it is misspelled, just that it is not pro- } \\
\text { vided in the dictionary. You may prevent the spelling } \\
\text { checker from questioning a specific word by adding it to } \\
\text { a custom dictionary and by this instructing the spelling } \\
\text { checker not to stop for it. }\end{array}$ & $\begin{array}{l}\text { all" button (2). } \\
\text { Click the "Add to Diction- } \\
\text { ary" button. }\end{array}$ \\
\hline Finish & $\begin{array}{l}\text { When completed spell checking, the spelling checker } \\
\text { closes the dialog. The user may also Cancel the dialog. }\end{array}$ & Click "Cancel" button. \\
\hline
\end{tabular}


The behaviorist model of learning has come under increasing attack in recent years. From widely diverse sources has come work that regards learning less as the product of passive transmission than a process of active construction.

Constructivism characterizes learning as the students' ability to construct their own understanding and capability based upon their prior knowledge and pre-understanding. This view of learning as construction is similar to Levi-Strauss's concept of "bricolage" or tinkering, a "science of the concrete" (Levi-Strauss, 1962). "Bricoleurs" construct concepts or theories by arranging and rearranging a set of well-known concrete materials.

There are two closely related theories of constructivism:

- Psychological/cognitive constructivism, and

- Social constructivism.

Psychological/cognitive constructivism represents a learning theory that considers organizing of knowledge in cognitive structures through assimilation and accommodation (Piaget, 1980).

Vygotsky (1978) developed and expanded Piaget's view, describing learning as a social interaction where the language plays an important role. Accordingly, learning occurs as learners exercise, test, and improve their knowledge through discussion, dialogue, collaboration, and information sharing. Vygotsky argued that the way learners construct knowledge, think, reason, and reflect on is uniquely shaped by their relationships with others.

An important tenet in Vygotsky's theory of social constructivism is what he calls "Zone of Proximal Development" (for short, "ZPD"): The distance between the actual development level as determined by independent problem solving and the level of potential development as determined through problem solving under adult guidance or in collaboration with more capable peers.

\section{ICT Training in Light of Learning Theories}

From the point of view of learning theory, traditional ICT training is clearly based on behaviorism. The focus is on memorizing, recall and reproduction of knowledge rather than conceptual understanding of the underlying software.

Herskin himself does not refer to learning theory to support or justify his method, but the authors of this paper can clearly draw a line from Herskin's view back to learning theorists such as Piaget and Vygotsky. Herskin's ICT training method uses constructivism in three different, but closely related ways:

- First, Herskin describes learning processes in a way that support well-known constructivist learning theory. Instead of imitation or repetition, knowledge is acquired through involvement with content and realistic problem solving (Kroll \& LaBosky, 1996). In Herskin's model, students acquire an understanding of the principles of the software, a procedural overview, and the ability to make practical use of these skills.

- Second, Herskin's understanding tools, among them visual explanations with "boxes" and "arrows", fit in well with Piaget's ideas of creating cognitive maps to organize knowledge.

- Third, Herskin is concerned about how to synchronize the students' thoughts through overview and summary in full group. He uses understanding tools in order to help the students to acquire the best possible understanding of the material. During the hands-on phase (the exercise), the objective is differentiating. Each student works at his/her own pace, and from his/her prerequisites. Any learning by co-operating is done through teacher-managed situations in the student group. 
However, in the opinion of the authors, there is a slightly lower degree of social constructivism in Herskin's method. Hence, it can be useful to let the students work together in the exercise phase. This might mean less differentiating of the students, but will increase the learning by co-operating in a higher degree than Herskin opens for.

Finally, according to Herskin, the method requires a deeper understanding of the principles behind the theory. Thus, further learning perspectives on Herskin's method could be:

- Superficial learning vs. deep learning

- Rote learning vs. meaningful learning

- Inductive (from specific problems and examples to general principles) vs. deductive method (from general instruction sheets to solving specific tasks)

\section{Research-Based Tasks}

The experimentation with Herskin's ICT training method was defined as compulsory researchand development task (R\&D) for students taking the course "Practical ICT Didactics" during the academic year of 2004-2005. Students were recommended to define their own research task.

During their teaching practice in upper secondary schools, which is an integral part of the Teacher Training Programme, they had to apply and evaluate the suitability of the method. This teaching practice had a duration of six weeks, from the end of January until the beginning of March 2005. The extent of the tasks differs from student to student.

There were 9 teacher students who participated in the experiment, an average of 20 school students in 9 different schools (about 180 school students), and 11 school teachers as supervisors.

The context in which the research was carried out is listed in Table 2, each row referring to one student's teaching subject and number of lessons at 45 minutes.

Table 2: Students' teaching subjects

\begin{tabular}{|l|c|}
\hline Subject & Duration \\
\hline $\begin{array}{l}\text { Creating forms and templates in the web development program Microsoft } \\
\text { FrontPage }\end{array}$ & $2 \times 2$ \\
\hline Creating diagrams using the spread sheet program Microsoft Excel & $2 \times 3$ \\
\hline $\begin{array}{l}\text { Connecting a database to a website using the database program Microsoft Ac- } \\
\text { cess and the web development program Microsoft FrontPage }\end{array}$ & $2 \times 1$ \\
\hline Using hyperlinks and style sheets in Microsoft FrontPage & $2 \times 2$ \\
\hline $\begin{array}{l}\text { Using hyperlinks, creating and changing backgrounds and font colours in Mi- } \\
\text { crosoft FrontPage }\end{array}$ & $2 \times 2$ \\
\hline Drawing graphs with the calculator simulating program TI-interactive & $1 \times 2$ \\
\hline Using Scientific Calculator (with advanced functions and derivation) & $3 \times 1$ \\
\hline Implementing the project management tool Microsoft Project & $1 \times 1$ \\
\hline Using basic functions in the photo imaging software Adobe Photoshop 6.0 & $3 \times 6$ \\
\hline
\end{tabular}

\section{Evaluation Methods}

Prior to their teaching practice, the students were presented to Herskin's ICT training method in lecture course of 3 hours duration. In addition to this presentation, they had to study Herskin's 
book "IT-training - the user in the centre" (Herskin, 2004a), which is a part of the required course reading material.

At the end of their practice, the students had to resume their experience in a project report paper. This report makes $40 \%$ of their portfolio, which is graded and presented at an oral exam. During the exam, they had to give feedback on their experiences and their understanding of the ICT training method. Each student was given this question during the oral exam: "What is the most important thing you have learned in the process of planning and teaching in accordance with Herskin's method?"

The qualitative paradigm (The Qualitative Research Report, 2004) was found to be suitable for evaluating the implementation of the understanding-oriented ICT user training method in upper secondary schools, mainly because the pre-study focused on learning processes as well as final outcomes, and personal aspects such as students' thoughts, feeling, actions, and learning difficulties.

Hence, to find out whether the students were able to apply the ICT training method in compliance with its basic principles, the following methods were used:

- Students' feedback on their experiences with the ICT training method and discussions during the oral exam.

- Analysis of students' written projects and education materials, and

- Observations of students' research work and discussions during the supervision of practical training

\section{Evaluation Results}

The evaluation results are presented with regard to the following issues:

1. Students' feedback on their experiences and understanding of the ICT training method

2. Teacher students' written project reports and associated teaching material

3. Observation of students' research activities and associated research-based tasks

\section{Students' Feedback and Experiences}

First, the paper examines teacher students' experiences and understanding of the ICT training method on the basis of their papers and oral discussions.

In the beginning, teacher students showed varying grade of motivation for the research assignment. In addition, when moving from the role of student to researcher, teacher students faced tremendous challenges. Many reported feeling frustration and stress, and even the desire not to do the research work. Some felt that they were unprepared to deal with a new method in real teaching jobs. Some students would prefer to choose their own research theme, others were rather afraid of trying out unfamiliar teaching methods in their early stage of teacher training.

However, at the end of project work, they considered the method to be well worth exploring and intended to apply it in their future teaching career.

When the teacher students were asked what they regarded to be their most important experience, the following main points were mentioned.

a) Responses from their own school students in secondary schools:

- School students liked the strict and logical structure of the method. 
- School students appreciated the method reducing the memory load.

b) Adapting the method as novice teacher students:

- Teacher students considered the method to be demanding and requiring considerable prework.

- Thinking they understood the method, working with it showed that they did not pick up important parts of the concept.

- Considering the instruction sheet as the method's main point, the students emphasized on elaborating this, failing to provide as much attention to other important parts of the method.

- Preparing lessons, the teacher students called attention to the lack of exemplary and approved course material. They asked for more examples, especially instruction sheets.

Some of the teacher students' other statements about how they considered the method to be used in schools were:

- "The method seems to be appropriate for adapted, differentiated teaching."

- "The method is developed and might fit best for older, mature students. It might be modified to fit the student's age and level."

- "The user may gain most from the method when using it for a longer period of time and becoming more familiar to it."

- "The method might be more suitable for well-defined and less complex problems."

\section{Teacher Students' Written Project Reports}

In this section, the article analyzes the teacher students' written project reports including teaching plan and teaching material. Students' implementations of the ICT training method revealed deviations from Herskin's postulates:

1. The overview phase should cover the "three P's": the Problem, the Principles, and the Procedural overview. A third of the students followed the method's main concept. The rest replaced parts of it with traditional teaching.

2. In the phase of hands-on training two elements should be available, introduction sheet (memo) and exercise(s). According to the method, instruction sheet and exercise are elements that should not be mixed. Half the students managed to separate them quite well, but the second half mixed them up. The quality varied among the students who got it right.

3. In the summary phase the following five topics can be covered: Questions from exercises, general issues, hints, supplementary mini-modules and transfer to users' daily tasks. However, the students did not put much work into the preparation of this part.

As a result, none of the students did implement the ICT training method in total compliance with its underlying principles, when applying it for the first time. Most of the teacher students had not been aware of their deviation; others knowingly made alternative choices, some of them in order to lighten their preparation work.

The following misconceptions or choices are considered to be most frequent:

- Teacher students paid most attention to the hands-on phase (exercise) and considerably less to the overview and summary phase. 
- Teacher students often integrated an exercise or parts of it into the instruction sheets. Doing so, they mixed up the two elements in the hands-on phase of the method, which Herskin regards to be essential to keep apart.

- Some teacher students mixed up the instruction sheet with an example or with several smaller examples. Their instruction sheets adapted the three columns (phase, why, interaction), but their contents were similar to tutorials guiding the user through specific tasks.

The project reports also referred to a singular but severe misinterpretation, which is always to keep blank the instruction sheet's column for interaction, leaving it to the user to write down the appropriate navigation threads and keystrokes.

In this regard, it might be necessary to stress that Herskin on one hand emphasizes the importance of supporting the user in navigating and helping him with difficult details (Herskin \& Herskin, 2005 ) and on the other hand requires the introduction sheets not to become too extensive. However, minimizing the instruction sheet blank too much will not provide the user with sufficient assistance. This paper considers preparing two variants of an instruction sheet to be a good idea, one slimmer "fill in" version to hand out first and one expanded richer version to be kept ready by the teacher (Herskin, 2004a).

Finally, teacher students emphasized explaining the method itself to their students in secondary schools in much larger scope than with other teaching methods. It might be natural to introduce teaching methods being new to the learners, but the students should not give more attention to introducing the method than to the subject itself.

\section{Teacher Students' Research Activities}

An important issue of this work is that the teacher students were functioning simultaneously as both teachers and researchers. Thus, it is important to illustrate how these competing roles played out (Cochran-Smith, 2005). The following issues are considered to be relevant to students' research activities:

- First, when it came to extent and subject for the research work, students experienced that their choices were limited. To be superimposed to do research on a new and specific ICT training method had not been totally motivating for the students. This is clearly a consequence of doing this kind of research within the limitations of the teaching practice in terms of allocated time and resources.

- Second, it turned out to be a problem to make room for trying out this kind of research in upper secondary schools. In many cases, the school timeframe had not been in line with the student's six weeks practice and the students' need for trying the new ICT training method.

- Third, the students' teaching practice supervisors (school teachers) did not have sufficient knowledge of the new ICT training method. Therefore, they could not provide the students with qualified supervision on planning and carrying out the teaching method. As a result, they did not encourage the students' motivation.

- Fourth, teacher students, on their own initiative, did not ask their academic supervisors for consistent help and guidance in connection with their research activities.

- Moreover, neither university teachers (academic supervisors) nor school teachers (practice supervisors) could provide sufficient teaching resources and documented experiences that may reused with some modifications as it was the first time that this kind of project work was carried out. 
- Furthermore, some of the teacher students had a superficial knowledge in both research methods and the teaching method to be tried out. As a result, it has been observed that not all teacher students reorganize their teaching radically. Some of them went on with a demo-oriented teaching concept (demonstrating the program functions on the big screen), but tried to improve the teaching by adapting minor parts of the ICT training method. This cannot be considered as trying out the new ICT training method.

- Finally, even if all teacher students chose "light versions", some of them uncritically, they think they had still acquired valuable experience, which enables them to change their teaching more radically in the future.

As a result, for future studies, where the objective is to generate evidence-based claims about the application of the ICT training method in upper secondary schools, it will be crucial that the teacher students follow the concept entirely. All parts of the method are important pieces that increase the benefit, and can not be excluded or replaced by alternatives. Small deviations often make a significant difference in this holistic method. In addition, the supervisors must ensure that the teacher students carry out their teaching in compliance with the ICT training method, and guide them past the pitfalls that they have experienced in this pre-study.

\section{Discussion}

Basically, from a theoretical point of view, the ICT training method has great potential for redesigning ICT training courses in a new light. It could have profound impacts on ICT training if properly implemented.

From a practical point of view, however, the production of novelty that is pedagogically and conceptually possible in the ICT training method, may be inhibited when it is introduced into educational settings where traditional views of teaching are actually predominant. It seems that the diffusion of ICT-based innovations within schools is a complex and gradual process, even under the most favourable conditions (Turin, Mioduser, Nachmias \& Forkosh-Baruch, 2003)

To discuss the implications of ICT training at upper secondary schools, it is important to identify critical factors of success that require attention to be given when introducing the ICT training method in upper secondary schools.

Analysis of the evaluation results collected from observations, discussions, and written project reports revealed that several factors may have directly or indirectly influence on the implementation of the ICT training method. These are:

- Teacher student's prior knowledge background

- Teaching subject and associated software tools

- Learning process and associated learning theories

- Learning resources, textbooks, and related study material

- School teachers as practice supervisors of teacher students

- University teachers as academic supervisors and initiators of the research project

- Learning assessment procedures

These factors are closely related to each other as the problems and difficulties encountered by the teacher students often resulted from interaction between those factors. 


\section{Teacher Students' Prior Knowledge Background}

The difficulties encountered by teacher students when implementing the new ICT training method for the first time are related to their prior knowledge background in computing and pedagogical research experience.

According to the constructivist learning theory, teacher students' prior knowledge could be significant epistemological obstacles for learning new knowledge (Steffe \& Gale, 1995; Wilson, 1998), or applying a new method like the one presented in this paper. For instance, students, who had learned ICT training through memorizing, recall, and knowledge reproduction, would probably regard conceptual understanding as unnecessary and would not integrate it into their ICT training lessons and practices. Like many teachers in education, teacher students would be inclined to teach the way they were taught. If they were taught a traditional ICT training approach, a way of thinking based on memorization, they would have few opportunities to apply the new teaching method based on conceptual understanding.

Even when teacher students, with sufficient prior knowledge in computing, were sufficiently motivated to apply the new ICT method as required, as this pre-study clearly demonstrates, they found the implementation of the method, in their attempt to translate theory to practice, be very demanding in terms of effort and time. In addition, they encountered difficulties of various types, e.g. insufficient help from supervisors, lack of well-designed examples and learning material, lack of documented experiences, limited time for reflection, etc.

It was thus not surprising that some teacher students continued to teach the ICT training lessons approximately in the same manner as traditional ICT training, changing a few details or focusing on one aspect of the new method, or mixing it up with traditional methods, without making fundamental changes to the way the new ICT method should be introduced into schools.

\section{Teaching Subject}

Basically, teacher students as practitioners at upper secondary schools experienced the understanding-oriented ICT training method in a variety of ways. They used a variety of software tools (FrontPage, Excel, Access, Microsoft Project, Photoshop, etc.) to teach different ICT subjects in informatics (database, Web design, graphic design, etc.)

According to the evaluation results, it appears that the ICT teaching subjects and the associated software tools being used affected the way teacher students implemented the ICT training method, and how they interpreted the underlying principles and concepts of the method, both positively and negatively according to their prerequisite knowledge and pre-understanding.

Software tools have various degree of complexity. For instance, there is a difference in the degree of complexity between spreadsheets and Microsoft FrontPage. It is thus important to understand software principles in terms of usability, functionality, detail richness, design criteria, etc. before applying the new ICT training method in upper secondary schools. Without the understanding the underlying principles of software, the degree of complexity of software tools could be a serious obstacle for applying the ICT training method (Herskin, 2004a).

Very important for the understanding of software functionality is the appropriate design of the instruction sheet. This illustrates the idea of brief, but powerful manual that may be used to understand a variety of software tools, in stark contrast to traditional ICT training courses, which strictly focus on memorization. Teacher students must learn the basic vocabulary of the instruction sheet at an early stage. Then, it will be easier to develop applications around the new concept, to ask a set of new questions about its application, and to make new explorations that were previously inaccessible with traditional ICT training methods. 
As a result, depending on the complexity of the software being used, teacher students will only gain mastery gradually through multiple cycles of implementing the ICT training method in all its dimensions (Bishop, Giles \& Bryant, 2005).

\section{Learning Process and Learning Theory}

Basically, teacher students experienced ICT training in a variety of ways. They used a variety of teaching methods (lectures, exercises, demonstrations, visualizations, dialogue, and similar methods) in their lessons. From a methodological point of view, however, they did not apply the ICT training method in complete accordance with the theory. Instead they mixed it up with elements of traditional teaching methods. Clearly, this is not sufficient to bring them to mastery of the ICT training method.

According to Herskin and practical experiences of university teachers, traditional ICT training methods do not encourage learners to think constructively in order to successfully understand the principles underlying software, because reproduction of knowledge, recall, and memorization of menus and buttons are still perceived as being primary at the expense of other modes of learning and thinking. The consequences of the traditional model of ICT training are a lack of conceptual understanding, insufficient skill acquisition, bad software use habits, and serious misconceptions of software principles.

As mentioned in previous sections, the very basis of the ICT training method is a pedagogical foundation based on the constructivist learning theory. Indeed, Herskin describes learning processes in a way that support well-known constructivist learning theory. Instead of imitation or repetition, knowledge is acquired through involvement with content and realistic problem solving (Kroll \& LaBosky, 1996). In Herskin's model, learners acquire an understanding of the principles of the software, a procedural overview, and the ability to make practical use of these skills. In addition, Herskin's understanding tools, among them visual explanations with "boxes" and "arrows", fit in well with Piaget's ideas of creating cognitive maps to organize knowledge.

Thus, unless teacher students give more attention to the constructivist learning theory and how it can be applied to ICT teaching courses, their ICT training practice cannot develop fully. This because progress in ICT training will only come from a better understanding of the learning process and the re-conceptualization of ICT teaching within learning theories, in particular cognitive and social constructivism, as well as situated learning (Phillip \& Soltis, 1998).

\section{University and School Teachers}

Teachers as supervisors of teacher students include a variety of people working on different levels. They do not share the same interests in or attribute the same meaning to ICT training. In fact, any ICT training method is socially constructed by a plurality of teachers according to their interests, needs, and competencies (Shields, 1994). Thus, teachers may limit or make the learning of the ICT training method possible.

Given the social construction of ICT training, the relevant issues may be addressed from different teacher's perspectives (Cochran-Smith, 2005), because the problems and difficulties encountered by teacher students often resulted from interactions with their supervisors involved in the research project work.

Thus, to understand how teachers as supervisors influence the implementation of ICT training, it may be necessary to look at the perspectives of the teachers involved in the supervision of teacher students when applying the new ICT training method:

- school teachers as practice supervisors of teacher students at upper secondary schools 
- university teachers as mentors, guides and academic supervisors of teacher students

\section{School teachers as practice supervisors}

Basically, school teachers could inhibit or even hinder the implementation of the ICT training method. This because schools are conservative social structures that resist challenges to redefine their teaching practice by integrating new pedagogical approaches (Grepperud, 1999).

When new ICT training methods like the one presented in this paper are incorporated into traditional practices, radical changes in ICT pedagogy could not be expected, for at least two reasons.

First, many school teachers do not have sufficient knowledge in the method being introduced in order to act as competent supervisors. Therefore, they could not provide the teacher students with qualified supervision on planning and carrying out ICT training.

Second, teachers' attitudes and beliefs affect the implementation of the ICT training method in ways that are consistent with instructional practices at their schools (Niederhauser \& Stoddart, 2001; Nordkvelle \& Olson, 2005).

As a result, to be successful, the re-conceptualization of ICT training within the understandingoriented ICT method requires a reworking of the ICT training courses given at schools. A new learning context must be created that promotes change in both pedagogy and course structure, in effect, altering multiple dimensions of the ICT training courses - the role and competency of school teachers, the expectations for teacher students, course material etc.

\section{University teachers as academic supervisors}

Obviously, the teaching of new ICT training methods requires both theoretical and practical knowledge, as well as the relevant experience of university teachers. But, more importantly, university teachers must be willing to teach new ICT training methods in their classes and must be confident in their ability to adapt them to the needs, abilities, and prerequisite knowledge of their students (Bitan-Friedlander, Dreyfus \& Milgrom, 2004). Clearly, unless new ICT training courses are given more attention on the university level, the development of ICT training practice at upper secondary schools cannot develop fully.

Three steps are important and necessary to lay the groundwork for a strong foundation of ICT training courses on the university level.

First, to produce a new generation of teacher students skilled in new ICT training methods, ICT didactics courses should be taught from the perspective of developing a strong pedagogical foundation of ICT training methods.

Second, the key concepts of ICT training must be taught consistently using a variety of software tools. By implementing the concepts using a variety of tools, teacher students learn to explore them on different levels. Teacher students trained in the new concepts are likely to understand ICT training in a new light.

Finally, new ICT training courses involve more than the theoretical understanding of ICT training concepts. The primary concern should not be limited to mastering concepts, but rather learning to use them to solve a variety of realistic ICT problems. This includes the ability to understand the relevant concepts, and to be able to apply them to solve interesting and realistic ICT problems. 


\section{Learning Resources}

Clearly, the diffusion of the understanding-oriented ICT training method is dependent on suitable textbooks and learning resources, which adequately address the underlying principles, concepts, and ideas.

Herkin's textbook (Herskin, 2004a) provides a theoretical foundation of the ICT training method. However, theoretical considerations in themselves are not sufficient to provide practical experience and skill development when using the new ICT training method, or help novice teacher students to understand the underlying principles of software (Hsu, 2004).

In addition, there is a lack of research literature about this innovative method. In other literature, there are few references to Herskin's material, and Herskin himself also has very few references to other literature. He provides the readers with very few practical examples of the teaching method. Herskin' aim is considered to be business-oriented, but this method is an appropriate issue for practical experiences and research work.

Hence, helping teacher students progress beyond the novice stage to higher-order levels of teaching ICT training courses, and thus, acquire mastery in ICT training methods, requires the development of appropriate training material and learning resources, as well as practical exercises that students consistently and continuously apply in their teaching.

\section{Learning Assessment Procedures}

Teacher students used a variety of assessment methods when evaluating the learning process of their own school students. Some used discussions and dialogue, while other used summative assessments, such as standard questionnaires. Finally, some teacher students did not evaluate the experiment at all. However, even when teacher students used some kind of assessment, the evaluation results revealed that assessment of the ICT method is relatively poor.

Summative assessment is the attempt to summarize learning at some point in time, say the end of a course. This is clearly not sufficient for assessing the value of the ICT training method.

In learning environments where the emphasis is on the acquisition of ICT training skills, summative assessments have advantages when it comes to assess factual recall and memorization, but they are not completely consistent with an understanding-oriented learning process that takes place in those environments.

By contrast, formative assessment occurs when teachers feed information back to students in ways that enable the students to learn better, or when students can engage in a similar, selfreflective process. Formative assessment is asking questions in order to determine the learners' current understanding, so that they can make adjustments if necessary (Beverly \& Bronwen, 2002). It is based on the principle that the evaluation of learning should not be separated from the learning process.

As a result, the ICT training method will be appropriately implemented only if both school and teacher students are evaluated formatively. To achieve this, the assessment of the value of the ICT training method should be embedded in the learning process and spread out over the duration of the teaching practice. This is however difficult to achieve given the conditions (schedule, time) of the experiments at upper secondary schools.

\section{Implications for ICT Training Courses}

An important implication of this pre-study is that teacher students need more guidance and tutoring on the ICT training method before implementing it in practice. The pre-study has made the 
authors of this paper aware of some critical misconceptions teacher students may encounter. Steps have to be taken in order to avoid such elements of risk.

It follows that in order to be successfully implemented in upper secondary schools, the ICT training method should be introduced according to the factors discussed in the previous section. Thus, factors of success in future studies will be:

1. To lay the groundwork for a pedagogical foundation of the ICT training method based on learning theories, in particular cognitive constructivism and social constructivism.

2. To give more attention to achieve pedagogical-theoretical foundation of ICT training method and the particular components of the method before the teacher students apply it in practice.

3. In the preparatory part of their project to give the student-researchers thorough practice in trying out the concept in the role of learners.

4. To underline the importance in implementing the ICT training method accurately without blending it with other concepts or teaching habits.

5. To provide learning material, appropriate exercises and suitable textbooks.

6. To provide more help and guidance both from university and school teachers.

7. To use assessment procedures which are embedded in the learning process.

\section{Conclusion}

The ICT training method presented in this paper is a potentially powerful method for improving ICT training courses in upper secondary schools. To exploit the full potential of the method requires the people involved in its application (university and school teachers, teacher students, and school students) to be initiated into all its aspects. The implementation entails changing the people's views and practices, and adopting the method in all its dimensions.

However, this can only be achieved through the iterative and continuous cycle of design, implementation, evaluation, and redesign of the ICT training method in varied schools contexts (The Design-Based Research Collective, 2003). The diffusion of ICT training innovations within schools is a complex and gradual process, even under the most favorable conditions.

The authors of this paper aim, in future studies, to explore the design and evaluation processes of the understanding-oriented ICT method in more details and depth in order to gain theoretical and practical insights, and, generate some evidence-based claims about the learning processes and further the current theoretical and practical knowledge of ICT training in upper secondary schools.

\section{References}

Beverly, B. F., \& Bronwen, C. (2002). Formative assessment and science education. London: Kluwer Academic.

Bishop, D. C., Giles, S. M., \& Bryant, K. S. (2005). Teacher receptiveness toward web-based training and support. Teacher and Teacher Education, 21, 3-14.

Bitan-Frielander, N., Dreyfus, A., \& Milgrom, Z. (2004). Types of "teachers in training": The reactions of primary school science teachers when confronted with task of implementing an innovation. Teacher and Teacher Education, 20, 607-619.

Cochran-Smith, M. (2005). Teacher educators as researchers: Multiple perspectives. Teacher and Teacher Education, 21, 219-225. 
The Design-Based Research Collective. (2003). Design-based research: An emerging paradigm for educational inquiry. Educational Research, 32 (1), 5-8.

Grepperud, G. (1999). Og skolen former i sitt bilde: Tvil og tro om IKT og skole. In Morgendagens @abc ITUs essaysamling. Forskings- og kompetansenettverk for IT i utdanning, Universitet i Oslo. Oslo: Strandberg \& Nilsen Grafisk AS.

Herskin, B. (2004a). IT-training - The user in the centre (in Danish. Original title: IT-undervisning - med brugeren i centrum). København: Nyt Teknisk Forlag, 4. oplag.

Herskin, B. (2004b). The IT pedagogical concept (Herskin model) (in Danish. Original title: Det ITpædagogiske koncept (Herskin-modellen)). Retrieved June 2, 2004, from: http://www.teachtoteach.dk/upload/application/c83bc19e/it-paedagogiske_koncept.pdf

Herskin, M.W., \& Herskin, B. (2005). Navigare necesse est - about modernization of user instructions (in Danish. Original title: Navigare Necesse est - om modernisering af brugervejledninger). Published 08.06.2005. Retrieved August 5, 2005, from: http://www.teachtoteach.dk/upload/application/c819d66f/navigare.pdf

Hsu, S. (2004). Using case discussion on the web to develop student teacher problem solving skills. Teacher and Teacher Education, 20, 681-692.

Kassbøll, J. (2002). Alternative to parrot training (Lecture Note). Department of Informatics, University of Oslo. Retrieved April 7, 2004, from: http://www.ifi.uio.no/infdid/Literature/AlternativeToParrot.pdf

Kroll, L. R., \& LaBosky, V. K. (1996). Practicing what we preach: Constructivism in a teacher education program. Action in Teacher Education, 18(2), 63-72.

Levi-Strauss, C. (1962). La pensée sauvage. Paris: Plon.

Lim, C. P., \& Tay, L. Y. (2003). Information and communication technologies (ICT) in an elementary school: Students' engagement in higher order thinking. Journal of Educational Multimedia and Hypermedia, 12(4), 425-451.

Niederhauser, D. S., \& Stoddart, T. (2001). Teachers' instructional perspectives and use of educational software. Teacher and Teacher Education, 17, 15-31.

Nordkvelle, Y. T., \& Olson, J. (2005). Visions for ICT, Ethics and the practice of teachers. Education and Information Technologies, 10(1/2), 19-30.

Piaget, J. (1980). The psychogenesis of knowledge and its epistemological significance: In M. PiatelliPalmarini (Ed.). Language and learning (pp. 23-34). Cambridge, MA: Harvard University Press.

Phillips, D.C., \& Soltis, J.F. (1998). Perspectives on learning. Columbia University: Teachers College Press.

The Qualitative Research Report. (2004). Retrieved March 3, 2005 from: http://www.nova.edu/ssss/QR/text.html

Sein, M.K., Bostrom, R., \& Olfman, L. (1998). Re-conceptualizing IT training for the workforce of the future. $A C M$ SIGCPR, 233-241.

Shield, M. A. (1994). Work and technology in higher education: The social construction of academic computing. New Jersey: Lawrence Erlbaum.

Steffe, L.P., \& Gale, J. (Eds.) (1995). Constructivism in education. New Jersey: Lawrence Erlbaum Associates.

Turin, D., Mioduser, D., Nachmias, R., \& Forkosh-Baruch, A. (2003). Domains and levels of pedagogical innovation in schools using ICT: Ten innovative schools in Israel. Education and Information Technologies, 8(2), 127-145.

Vygotsky, L.S. (1978). Mind and society: The development of higher mental processes. Cambridge, MA: Harvard University Press. 
Wilson, B. G. (1998). Constructivist learning environments: Case studies instructional design. New Jersey: Educational Technology Publications.

\section{Biographies}

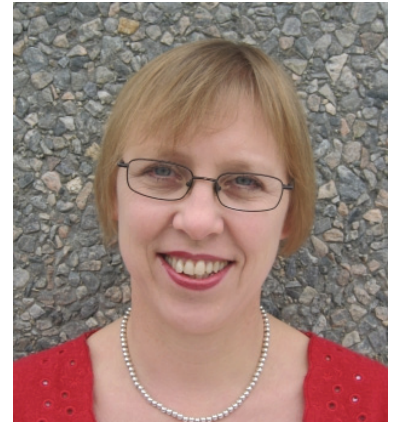

Cornelia Brodahl is an Assistant Professor and lecturer at the Faculty of Mathematics and Sciences at Agder University College, Kristiansand (Norway), from 2001. She received the master degree in Mathematics from the University of Münster (Germany) in 1979 and is currently working towards a professional doctorate. She has been in the teaching profession since 1980 and worked as system analyst in industry in 1998-2001. Her research and teaching interests include ICT and learning, and Professional ICT Didactics. Main areas of expertise and interest are ICT supported learning, digital teaching aids, pedagogical web design, and didactical animations in mathematics.

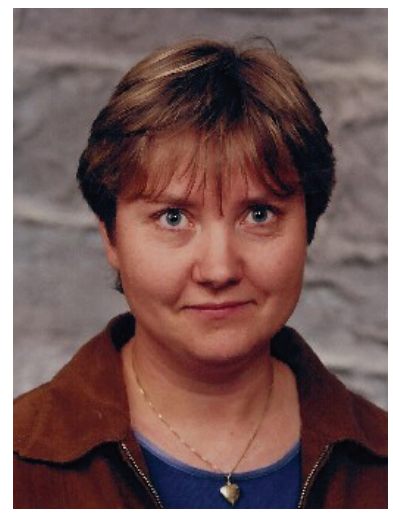

Marit Fagernes has been in the teaching profession for almost 20 years, and has a teacher's degree from Bergen University College (Norway), 1987. She has broad experience as a teacher in compulsory school, as well as ICT training courses and as a lecturer at higher education studies. In 2003, she completed a 2-year undergraduate degree in Information Management, Sør-Trøndelag University College, Trondheim (Norway). From 2003 throughout 2006 she has worked as an Assistant Professor and lecturer at courses in ICT and learning and Didactics in ICT, at Agder University College, Kristiansand (Norway). She is currently employed by Department of Education in the Municipality of Lindesnes (Norway), as an IT Advisor. Main areas of expertise and interest are ICT in education, adapting ICT-based learning environments, use of open source software in education.

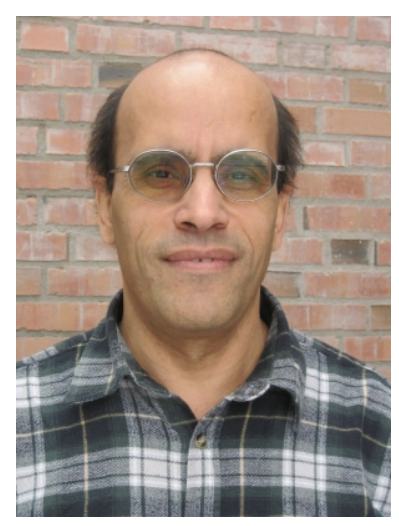

Said Hadjerrouit received the MS and $\mathrm{PhD}$ degrees in Software Engineering and Artificial Intelligence from the Technical University of Berlin (Germany), in 1985 and 1992, respectively. He joined Agder University College, Kristiansand (Norway) in 1991. He is currently an Associate Professor of Computer Science at the Faculty of Mathematics and Sciences. He has been in the teaching profession for 25 years. He has extensive experience in teaching object-oriented programming, Web engineering, database development, software engineering, and didactics of informatics. His research interests include object-oriented software development with UML, computer science and software engineering education, didactics of informatics, use of ICT in mathematics education, development of Web-based learning systems and eLearning. Hadjerrouit has published over 45 papers in international journals and conference proceedings. 